\title{
Self-Attribution Bias in Financial Decision Could Be Decreased with Resilience? A Study on Resilience Centered Training
}

\section{Çăgrı HAMURCU ${ }^{1}$}

\section{ARTICLE INFO}

Article History:

Date Submitted: 19.03.2019

Date Accepted: 15.05.2019

\begin{tabular}{l}
\hline JEL Classification: \\
D90 \\
D91 \\
G40 \\
G41
\end{tabular}

Keywords:

Behavioral Finance,

Self-Attribution Bias,

Resilience,

Resilience Centered

Training,

Resilience Scale for Adults.

\begin{abstract}
Topic: This is the first study to focus on the self-attribution bias in financial decision and resilience relation. Resilience is one of the empowering factor to alleviate the negative effects of stressors and adversities, to comply with the new situations and to think in realistic way. When considered this point of view, selfattribution bias in financial decision and resilience relation could be an important subject.
\end{abstract}

Background: There is no any scientific work about the subject of the selfattribution bias in financial decision and resilience relation. In this study it is aslo analyzed the effect of resilience trainings on self attribution bias and resilience.

Purpose/Aim: One of the aims of this work is to invesitegate the self-attribution bias in financial decision and resilience correlation. The other aim is to find an evidence of how the self-attribution bias in financial decision and resilience changes with resilience centered trainings.

Scope/Method: For this reason, individual self-attribution bias and resilience scores are measured. In order to measure the self attribution bias, specific statemens about the bias are conducted. To evaluate the resilience scores, The Turkish version of the Resilience Scale for Adults is used.

Results: The results show firstly, there is a negative relation between the self attribution bias and the resilience. Secondly it is seen that, the self attribution bias scores are decreased and the resilience scores are increased after the resilience centered trainings.

Conclusions: Importantly, our results provide the evidence about the relation of self attribution bias and resilience and the effect of resilience centered trainings on these factors. On the other hand, it is needed more research studies to validate and understand these findings.

\footnotetext{
${ }^{1}$ Independent Researcher, cagri.hamurcu@gmail.com
} 


\section{INTRODUCTION}

This is the first study to focus on the self-attribution bias in financial decisions and resilience relation. When considered this point of view, self-attribution bias in financial decisions and resilience relation could be an important subject.

There is no any scientific work about the subject of the self-attribution bias and resilience relation. In this study it is also analyzed the effect of resilience trainings on self-attribution bias and resilience.

One of the aims of this work is to investigate the self-attribution bias in financial decision and resilience correlation. Another aim is to find an evidence of how the self-attribution bias in financial decision and resilience changes with resilience centered trainings.

\section{Self-Attribution Bias}

During the decision making process under the risky and uncertain situations, behavioral tendencies that include anomalies compared to rational situations could be more effective (Hamurcu and Hamurcu, 2017).

Self-Attribution Bias is a tendency to think in a way that success is related to personal skills and failure is related to an external factor beyond their control (Wolosin et al., 1973; Schneider et al., 1979, Doukas\&Petmezas, 2007).

The studies on the subject of self-attribution bias is gaining an increased attention in household finance (Hoffmann\&Post, 2014). It is stated in the studies that it has a strong relation with overconfidence, overinvestment (Daniel et al., 1998, Barber and Odean, 200, Dorn and Huberman, 2005, Statman et al., 2006), and under diversification (Goetzmann and Kumar, 2008).

Self-attribution bias is examined in two subgroups (Pompian, 2006: 104): 
Self-enhancing bias: It causes to an irrational thinking on behalf of self-attributed success.

Self-protecting bias: It leads to a non-rational rejection of failure for responsibility.

Investors, who tend to self-attribution errors, will attribute their failures and wrong decisions to external resources, exaggerate the right decisions and will not perceive the real situation and will be able to repeat their mistakes without being aware of them.

In the study of Doukas\&Petmezas (2007), it is found that managerial overconfidence result from self-attribution bias.

Errors classified under the self-attribution bias have a stronger impact on investors and therefore investors suffer from their own cognitive inabilities (Yalçın, 2009).

Another study on self-attribution bias is the study of Mishra \& Metilda (2015). The findings of this study is that there is a positive relation between self-attribution bias and education, but there is no significant relation between self-attribution bias and gender, investor's experience.

\section{Resilience}

Resilience is one of the empowering factor to alleviate the negative effects of stressors and adversities, to comply with the new situations and to think in realistic way (Pemberton, 2015). Another explanation of the resilience is, although important risks for development in a healthy way, to achieve good outcomes by adopting easily (Masten, Hubbard, Gest, Tellegen, Garmezy \& Ramirez, 1999). Resilience is more about wellness rather than pathology (Hawley \& DeHaan, 1996).

To mitigate the negative effects of stressors and risks, an individual develops a process to have some competences and strengths by using its internal and external resources (Rutter, 1990; Yates, Egeland \& Sroufe, 2003).

The term of resilience was first taken into consideration in engineering, it means that the capability to endurance to stressful conditions and returning to its original state (Holling, 1973). 
Much afford on resilience studies was structured on health promoting factors. These studies have not really focused on measuring the resilience in a correct way. Instead these were focused on indirect indicators such as intelligence, personality, family relations, social support etc. (Friborg, 2005).

Lots of the studies have been held to investigate the nature of the resilience (Wagnild \& Young, 1993; Baruth \& Carroll, 2002; Connor \& Davidson, 2003; Friborg et all., 2003; Oshio, Kaneko, Nagamine\&Nakaya, 2003; Sinclair \& Wallston, 2004). In 2005, Friborg et all, was developed a new scale explaining the resilience model in a better way with six dimension: perception of self, perception of the future, structured style, social competence, family cohesion and social resources. This scale is known the latest version of The Resilience Scale for Adults (RSA).

Resilience training is one of the common methods for developing the resilience. In the study performed by Joyce et all (2018), participants reported greater levels of resilience after the training program. Thompson\& Dobbins (2018) investigated that resilience training was a compelling and necessary avenue for further research.

On the contrary there is no enough number of scientific evidence on how this trainings affect the resilience. In this study it is analyzed the effect of resilience trainings on individual resilience.

\section{Hypothesis}

This study has three hypotheses:

Hypothesis 1: There is a negative correlation between self-attribution bias in finance and resilience.

Hypothesis 2: Self attribution bias in finance decreases with resilience centered trainings.

Hypothesis 3: Resilience increases with resilience centered trainings. 


\section{METHODS}

This research was carried out in five stages; literature research study, preparation of forms, announcing the study, receive the application, applying this form to the research group before the resilience training, giving 8 hours long training program developed specifically to improve the individual resilience, applying this form to the research group again after the resilience training and evaluating the statistical analysis to the obtained data.

In the study, three different forms were used to measure self-attribution bias, resilience scale and socio-demographic factors. All analyzes were performed using SPSS Ver.20.

In order to measure the self-attribution bias, specific statements about the bias are conducted. To evaluate the resilience scores, Turkish version of The Resilience Scale for Adults (Basım\&Çetin, 2011) is used.

To calculate the self-attribution bias above written statements were asked to participants and the participants answered these statements with 5- point Likert type scale from strongly disagree to strongly agree.

Statement 1: I believe that success in my investment decisions stem from my personal skills. Statement 2: I believe that failure in my investment decisions is mostly outsourced or by chance.

The RSA is composed of self-report 33 items with six dimensions: Perception of self-perception of the future, structured style, social competence, family cohesion and social resources. In order to evaluate the resilience score correctly, it is important to convert the negative items to the positive ones. After this, points of 33 items are added to each other. The result gives the resilience score. The higher resilience scores means the resilience with higher levels and the lower resilience scores means the resilience with lower levels.

There are 4 sociodemographic questions in the form: age, marital status, gender and the level of education. 
This qualitative study is performed to 45 volunteer in Ankara between September-December 2018 and January-February 2019 with five separate sessions. In each session, above mentioned three forms are applied to the participants one to one.

Wilcoxon Signed Rank and Kruskal Wallis H tests are applied to obtained data for comparing the resilience scores and finding the relation between sociodemographic factors and resilience scores respectively.

\section{RESULTS}

Analysis of the obtained data revealed below explained findings and contributions.

Table 1: Sociodemographic Distribution of the Participants

\begin{tabular}{lrrrrrr}
\hline & $20-29$ & $30-39$ & $39+$ \\
Age & 37.8 & $\%$ & 15.6 & $\%$ & 46.7 & $\%$ \\
\hline \multirow{4}{*}{ Gender } & Female & Male & & \\
\hline & 82.2 & $\%$ & 17.8 & $\%$ & \\
Marital Status & Married & Single & & \\
\hline & 51.1 & $\%$ & 48.9 & $\%$ & & \\
Level Of Education & High School & & Associate Degree & & Undergraduate & \\
\hline
\end{tabular}

Table.1 shows sociodemographic distribution of the participants by age, gender, marital status and level of education.

The reliability values of the obtained self-attribution bias data before and after the resilience training are 0.701 and 0.733 respectively.

The reliability values of the obtained RSA data before and after the resilience training are 0.910 and 0.922 respectively.

When the subject comes to self-attribution and resilience relation, in order to evaluate whether there is a correlation or not, the Spearman's correlation test is applied. 
Table 2: Spearman's Correlation Test Results

\begin{tabular}{|c|c|c|c|c|}
\hline \multicolumn{5}{|c|}{ Correlations } \\
\hline \multicolumn{3}{|c|}{ Before the training } & Resilience & Self-attribution \\
\hline \multirow{6}{*}{ Spearman's rho } & \multirow{3}{*}{ Resilience } & Correlation Coefficient & 1.000 & $-.554^{* *}$ \\
\hline & & Sig. (2-tailed) & & .000 \\
\hline & & $\mathrm{N}$ & 45 & 45 \\
\hline & \multirow{3}{*}{ Self-attribution bias } & Correlation Coefficient & $-.554^{* *}$ & 1.000 \\
\hline & & Sig. (2-tailed) & .000 & \\
\hline & & $\mathrm{N}$ & 45 & 45 \\
\hline \multicolumn{3}{|l|}{ After the training } & Resilience & Self-attribution \\
\hline \multirow{6}{*}{ Spearman's rho } & \multirow{3}{*}{ Resilience } & Correlation Coefficient & 1.000 & $-.629^{* *}$ \\
\hline & & Sig. (2-tailed) & & ,000 \\
\hline & & $\mathrm{N}$ & 45 & 45 \\
\hline & \multirow{3}{*}{ Self-attribution bias } & Correlation Coefficient & $-.629^{* *}$ & 1.000 \\
\hline & & Sig. (2-tailed) & .000 & \\
\hline & & $\mathrm{N}$ & 45 & 45 \\
\hline
\end{tabular}

Table 2 shows that, there is a negative correlation between self-attribution bias and resilience both before and after the training.

In order to compare the change in self-attribution bias before and after the training and RSA values before and after the training, Wilcoxon Signed Ranks Test is applied. In Table 3, it is seen that all the values in the row of Asymp. Sig. is less than 0.05. These values indicate that there is a statistically significant difference between the values of self-attribution bias before and after the training and RSA scale scores before and after the training. 
Table 3: Wilcoxon Signed Ranks Test Results

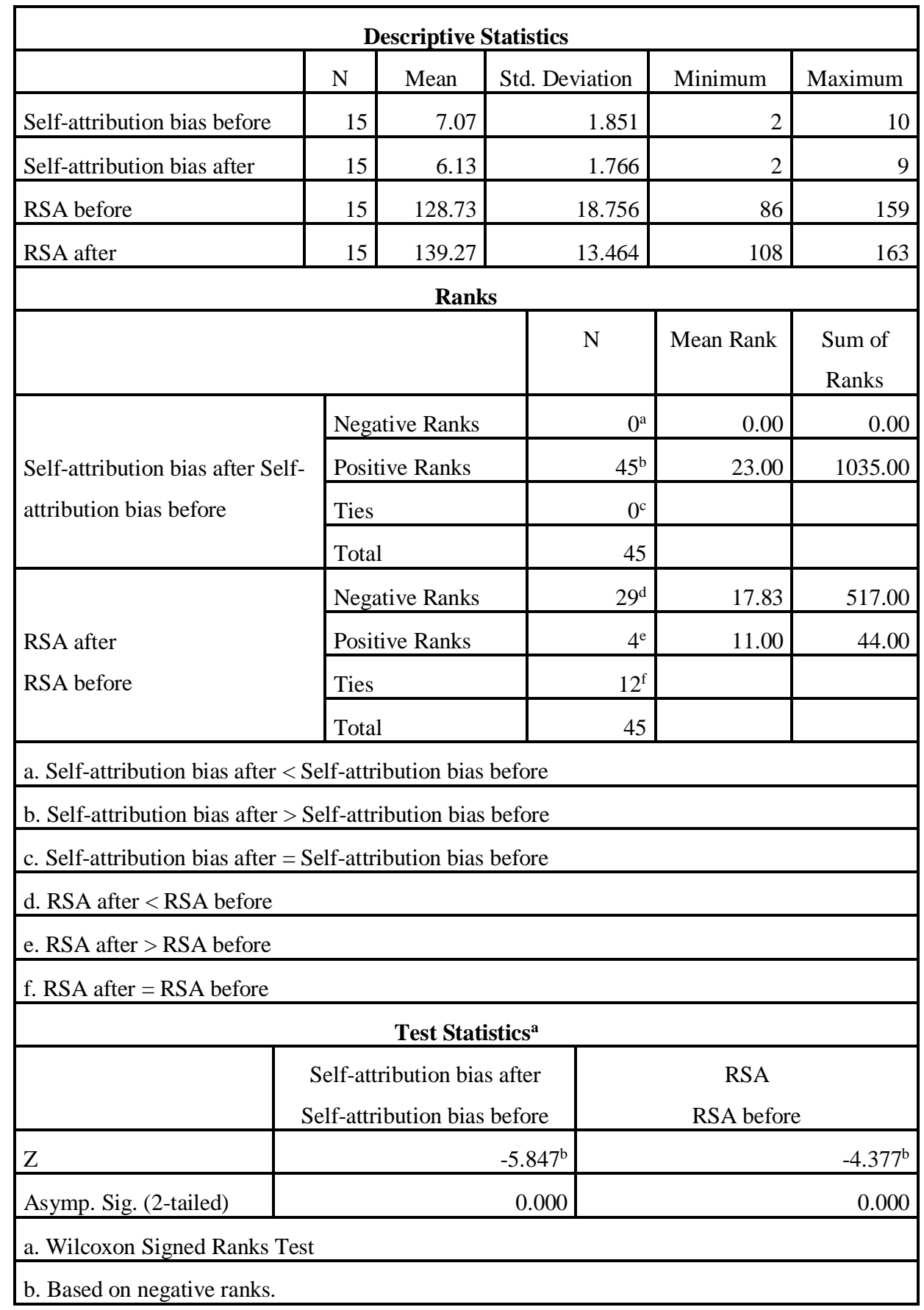

It is seen on the Table 3 that, descriptive statistics shows that the mean value of self-attribution bias after the training is smaller than the before ones. On the other hand, RSA score after the resilience training program is greater than the before ones. RSA score changes are consistent with previous studies (Joyce et.all, 2018, Thompson\& Dobbins, 2018). 
Kruskal Wallis $\mathrm{H}$ Test is applied to obtained data for finding the relation between sociodemographic factors and self-attribution bias and resilience scores respectively. According to analysis, there is no statistically significant relation between self-attribution bias and sociodemographic factors (age, gender, marital status and education). In addition, same results are found between resilience and sociodemographic factors

\section{CONCLUSION AND DISCUSSION}

The results show firstly, there is a negative relation between the self-attribution bias and the resilience. In other words, when resilience increases, the self-attribution bias decreases. This confirms Hypothesis 1. This result suggests that by increasing the resilience, which is an improved competence, self-attribution bias one of the behavioral finance biases could be decreased. This relation could give a possibility to reduce the financial anomalies.

Secondly it is seen that, after the resilience centered training programs the self-attribution bias scores are decreased and the resilience scores are increased. These findings confirm Hypothesis 2 and 3. While self-attribution scores are declined after the training program, RSA scores after the resilience training program are scaled up. This result gives us some clues in how to weaken the self-attribution bias and make more resilient people. By resilience centered training programs, financial anomalies could be decreased.

The second result of this study are consistent with previous studies. Joyce et. all (2018) reported greater levels of resilience after the training program compared to baseline. Thompson\& Dobbins (2018) investigated that resilience training for active duty service members was compelling. Importantly, these results provide the evidence the importance of the resilience training to develop the resilience.

Thirdly, it is found that there is no significant relation between self-attribution bias, resilience and age, gender, marital status and level of education. This result could be interpreted that there could be other determinants of self-attribution bias and resilience apart from that factors. On 
the other hand, it is needed more research studies to understand how self-attribution bias and resilience changes with sociodemographic factors.

One of the limitation of this study is the number of participants. This limitation might be addressed in future studies. In future, more research studies should be carried out to investigate the unknown nature of the resilience.

\section{REFERENCES}

Baruth, K. E., \& Carroll, J. J. (2002). A formal assessment of resilience: The Baruth Protective Factors Inventory. Journal of Individual Psychology, 58, 235-244.

Basım, H. N., \& Çetin, F. (2011). Yetişkinler için psikolojik dayanıklılık ölçeğinin güvenilirlik ve geçerlilik çalışması. Türk Psikiyatri Dergisi, 22(2), 104-114.

Connor, K. M., \& Davidson, J. R. (2003). Development of a new resilience scale: The ConnorDavidson resilience scale (CD-RISC). Depression and anxiety, 18(2), 76-82.

Doukas, J. A., \& Petmezas, D. (2007). Acquisitions, overconfident managers and selfattribution bias. European Financial Management, 13(3), 531-577.

Friborg, O., Hjemdal, O., Rosenvinge, J. H., \& Martinussen, M. (2003). A new rating scale for adult resilience: what are the central protective resources behind healthy adjustment? International journal of methods in psychiatric research, 12(2), 65-76.

Friborg, O. (2005). Validation of a scale to measure resilience in adults. Department of Psychology, Faculty og social Sciences, University of Troms $\emptyset$.

Friborg, O., Barlaug, D., Martinussen, M., Rosenvinge, J. H., \& Hjemdal, O. (2005). Resilience in relation to personality and intelligence. International journal of methods in psychiatric research, 14(1), 29-42.

Hamurcu, Ç., \& Hamurcu, H. D. Y. (2017). How Depression And Social Media Preferences Affect Financial Investment\&Gambling Risk Taking Behaviours. Journal of Life Economics, 4(4), 143-156.

Hawley, D. R., \& DeHaan, L. (1996). Toward a definition of family resilience: Integrating lifespan and family perspectives. Family process, 35(3), 283-298. 
Hoffmann, A. O., \& Post, T. (2014). Self-attribution bias in consumer financial decisionmaking: How investment returns affect individuals' belief in skill. Journal of Behavioral and Experimental Economics, 52, 23-28.

Holling, C. S. (1973). Resilience and stability of ecological systems. Annual review of ecology and systematics, 4(1), 1-23.

Joyce, S., Shand, F., Bryant, R. A., Lal, T. J., \& Harvey, S. B. (2018). Mindfulness-Based Resilience Training in the Workplace: Pilot Study of the Internet-Based Resilience@ Work (RAW) Mindfulness Program. Journal of medical Internet research, 20(9), e10326.

Masten, A. S., Hubbard, J. J., Gest, S. D., Tellegen, A., Garmezy, N., \& Ramirez, M. (1999). Competence in the context of adversity: Pathways to resilience and maladaptation from childhood to late adolescence. Development and psychopathology, 11(1), 143-169.

Mishra, K. C., \& Metilda, M. J. (2015). A study on the impact of investment experience, gender, and level of education on overconfidence and self-attribution bias. IIMB Management Review, 27(4), 228-239.

Oshio, A., Kaneko, H., Nagamine, S., \& Nakaya, M. (2003). Construct validity of the adolescent resilience scale. Psychological Reports, 93, 1217 - 1222.

Pemberton, C. (2015). Resilience: A Practical Guide for Coaches. Open University Press.

Rutter, M. (1990). Psychosocial resilience and protective mechanisms. In Rolf, J., Masten, A. S., Cicchetti, D., Neuchterlein, K. H., \& Weintraub, S. (Eds.), Risk and protective factors in the development of psychopathology (pp. 181-214). New York: Cambridge University Press.

Schneider, D. J., Hastorf, A. H. and Ellsworth, P. C., Person Perception, 2nd edn (AddisonWesley, 1979).

Sinclair, V. G., \& Wallston, K. A. (2004). The development and psychometric evaluation of the Brief Resilient Coping Scale. Assessment, 11(1), 94-101.

Thompson, S. R., \& Dobbins, S. (2018). The Applicability of Resilience Training to the Mitigation of Trauma-Related Mental Illness in Military Personnel. Journal of the American Psychiatric Nurses Association, 24(1), 23-34.

Wagnild, G. M., \& Young, H. M. (1993). Development and psychometric evaluation of the Resilience Scale. Journal of nursing measurement. 
Wolosin, R. J., Sherman, S. J. and Till, A., 'Effects of cooperation and competition on responsibility attribution after success and failure', Journal of Experimental Social Psychology, Vol. 9, 1973, pp. 220-35.

Yalçın, K. C. (2010). Market rationality: Efficient market hypothesis versus market anomalies. European Journal of Economic and Political Studies, 3(2), 23-38.

Yates, T. M., Egeland, B., \& Sroufe, A. (2003). Rethinking resilience. Resilience and vulnerability: Adaptation in the context of childhood adversities, 243-266. 